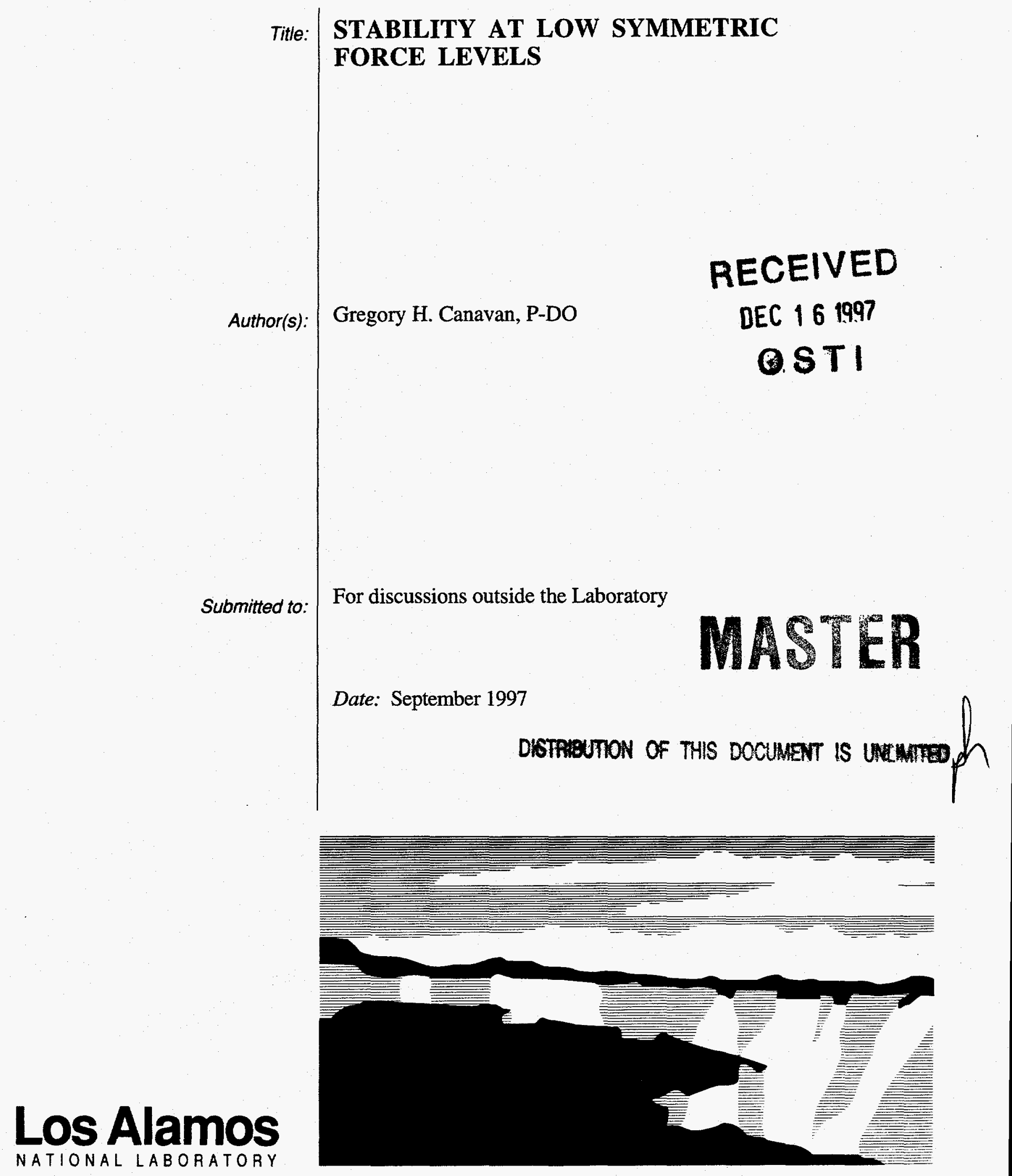

Los Alamos National Laboratory, an affirmative action/equal opportunity employer, is operated by the University of California for the U.S. Department of Energy under contract W-7405-ENG-36. By acceptance of this article, the publisher recognizes that the U.S. Government retains a nonexclusive, royalty-free license to publish or reproduce the published form of this contribution, or to allow others to do so, for U.S. Government purposes. The Los Alamos National Laboratory requests that the publisher identify this article as work performed under the auspices of the U.S. Department of Energy. 


\section{DISCLAIMER}

This report was prepared as an account of work sponsored by an agency of the United States Government. Neither the United States Government nor any agency thereof, nor any of their employees, makes any warranty, express or implied, or assumes any legal liability or responsibility for the accuracy, completeness, or usefulness of any information, apparatus, product, or process disclosed, or represents that its use would not infringe privately owned rights. Reference herein to any specific commercial product, process, or service by trade name, trademark, manufacturer, or otherwise does not necessarily constitute or imply its endorsement, recommendation, or favoring by the United States Government or any agency thereof. The views and opinions of authors expressed herein do not necessarily state or reflect those of the United States Government or any agency thereof. 


\section{DESCLAMER}

Portions of this docoment may be illegibie in electronic ironge products. Images are produced from the best arritable original docoment. 


\title{
STABILITY AT LOW SYMMETRIC FORCE LEVELS
}

\author{
Gregory H. Canavan
}

\begin{abstract}
At low force levels stability indices depend primarily on the number of vulnerable missiles and the number of weapons on them. The index reduces to a product of the number of vulnerable missiles and the difference between normalized second and first strikes by vulnerable weapons. As the number of weapons per vulnerable missile decreases, the index rapidly approaches stability. Further reductions in vulnerable and survivable missiles and weapons do not affect stability, although they do reduce first and second strikes. Modest weapon reconstitution degrades stability significantly.
\end{abstract}

Companion papers discuss the stability of strategic configurations ranging from current missile forces to START III. This note discusses the variation of strikes and stability indices at still lower force levels to see if any new concerns are raised there. It uses an aggregated, probabalistic exchange model, whose strikes, costs, and indices are used to study stability at force levels smaller than the number of value targets held at risk, in which case costs, indices, and optimal allocations are rigorously linear in the forces.

In this limit, stability indices depend primarily on the number of vulnerable missiles and the number of weapons on them. The number of survivable weapons cancels out, as the number of survivable weapons delivered is the same in first and second strikes. The stability index reduces to a bilinear product of the number of vulnerable missiles and the difference between the normalized second and first strikes by vulnerable weapons.

As the number of weapons per vulnerable missile decreases, the number of weapons allocated to each vulnerable missile decreases, its survival probability falls, and the second strike is constant. Thus, the first strike increases almost as rapidly as the number of weapons, and the difference index rapidly approaches stability. Decreasing the kill probability of vulnerable weapons increases stability. Increasing the attacker's preference for damage to other shifts weapons from counterforce to countervalue attacks, but has little overall impact on stability.

The bilinear low-force stability index means that stability can be gained at any number of missiles by reducing the number of weapons per vulnerable missile to unity. Once that is done, further reductions in vulnerable and survivable missiles and weapons do not affect stability, although they do reduce first and second strikes.

The end point of most arms-control discussions is a modest number of single-weapon vulnerable missiles and many survivable weapons. The analysis above indicates that the latter is irrelevant, but that this configuration would be stable. Increasing the number of vulnerable single-weapon missiles would not alter the stability index. Increasing the number of weapons per 
vulnerable missile would decrease stability for any number of vulnerable missiles. Doubling the number of weapons per missile would decrease the stability index significantly. The number of weapons required for that shift would be an additional warhead per missile times the number of vulnerable missiles, which need not be large.

Exchange Model. Appendix A describes the aggregated, probabilistic interaction of two arbitrary missile forces, in which exchanges are modeled in terms of the first and second strikes each side could deliver. ${ }^{1}$ In this note the two sides are assumed to have identical missile forces. Each side has $M$ vulnerable missiles with $\mathrm{m}$ weapons each and $\mathrm{N}$ survivable missiles with $\mathrm{n}$ weapons each. The side that strikes first allocates a fraction $f$ of his total of $W=m M+n N$ weapons on the other side's $M$ vulnerable missiles, which gives $r=f W / M$ weapons per missile. The remaining weapons constitute his first strike on value targets, which is

$$
F=(1-f)(m M+n N)=(1-f) W,
$$

The average survival probability of vulnerable missiles is $Q \approx q^{r}$, where $p=1-q$ is the missile single shot probability of kill. Thus, the second strike is of magnitude

$$
\mathrm{S}=\mathrm{QmM}+\mathrm{nN} \text {. }
$$

Costs and indices. These first and second strikes are converted into first and second strike costs through exponential approximations to the fractions of military value targets destroyed, as described in Appendix B. The calculations below assume that each side has $1 / \mathrm{k} \sim$ 1,000 value targets. The cost of damage to self and incomplete damage to other are joined in a weighted average with a parameter $\mathrm{L}$, which measures the attacker's relative preference for damage to the other and prevention of damage to self. ${ }^{2}$ For the small forces of interest here, the costs of striking first and second simplify to ${ }^{3}$

$$
\begin{aligned}
& (1+\mathrm{L}) \mathrm{C}_{1} \approx \mathrm{kS}+\mathrm{L}(1-\mathrm{kF})=\mathrm{k}[\mathrm{QmM}+\mathrm{nN}]+\mathrm{L}[1-\mathrm{k}(\mathrm{W}-\mathrm{rM})], \\
& (1+\mathrm{L}) \mathrm{C}_{2} \approx \mathrm{kF}+\mathrm{L}(1-\mathrm{kS})=\mathrm{k}[\mathrm{W}-\mathrm{rM}]+\mathrm{L}[1-\mathrm{k}[\mathrm{QmM}+\mathrm{nN}] .
\end{aligned}
$$

For small $\mathrm{F}$ and $\mathrm{S}$, the cost ratio stability index is approximately ${ }^{4}$

$$
\mathrm{I}=\mathrm{C}_{1} / \mathrm{C}_{2} \approx 1+\left(\mathrm{C}_{1}-\mathrm{C}_{2}\right)(1+\mathrm{L}) / \mathrm{L}=(1+\mathrm{L}) / \mathrm{L} \mathrm{k}(\mathrm{S}-\mathrm{F}),
$$

where $I \approx 1$ denotes stability, so an appropriate stability index for small forces is

$$
\mathrm{J}=(\mathrm{I}-1) \mathrm{L} /(1+\mathrm{L}) \approx \mathrm{k}(\mathrm{S}-\mathrm{F})=\mathrm{k}(\mathrm{QmM}+\mathrm{nN})-\mathrm{k}(\mathrm{W}-\mathrm{rM})
$$

where $\mathrm{J} \approx 0$ denotes stability.

Attack allocation. First strikes are optimized by minimizing the cost of executing them, ${ }^{5}$ as determined by Eq. (3), through the analytic optimization described in Appendix $\mathrm{C}^{6}{ }^{6}$ which is sufficiently accurate for the modest force levels treated here. ${ }^{7}$ The result is

$$
\mathrm{f}=(\mathrm{M} / \mathrm{W} \ln q) \ln (-\mathrm{L} / \mathrm{mln} q) \text {, }
$$


which depends directly on $\mathrm{M} / \mathrm{W}$ and logarithmically on $\mathrm{L} / \mathrm{m}$ and $\mathrm{q}$. The number of weapons allocated to vulnerable missiles is $\mathrm{fW}=\mathrm{M} \ln (-\mathrm{L} / \mathrm{mlnq}) / \mathrm{nq}=\mathrm{rM}$, which could be satisfied by vulnerable missiles as long as $\mathrm{r}<\mathrm{m}$, as is the case below. With this allocation the average number of weapons per vulnerable missile is

$$
\mathrm{r}=\mathrm{fW} / \mathrm{M}=\ln (-\mathrm{L} / \mathrm{mlnq}) / \mathrm{lnq},
$$

and the survival probability is

$$
\mathrm{Q} \approx \mathrm{q}^{\mathrm{r}}=-\mathrm{L} / \mathrm{mln} \mathrm{q} .
$$

so that $\mathrm{r}$ and $\mathrm{Q}$ are determined by $\mathrm{L} / \mathrm{m}$ and $\mathrm{q}$.

Strikes. With optimal allocation, the first strike is

$$
\mathrm{F}=(1-\mathrm{f}) \mathrm{W}=[1-(\mathrm{M} / \mathrm{W} \operatorname{lnq}) \ln (-\mathrm{L} / \mathrm{mln} q)] \mathrm{W}=\mathrm{mM}+\mathrm{nN}-(\mathrm{M} / \mathrm{lnq}) \ln (-\mathrm{L} / \mathrm{mlnq}) \text {, }
$$

and the second strike is

$$
\mathrm{S}=\mathrm{QmM}+\mathrm{nN}=-\mathrm{ML} / \mathrm{hq}+\mathrm{nN},
$$

so the difference between them is

$$
\begin{aligned}
\mathrm{S}-\mathrm{F}= & \mathrm{QmM}+\mathrm{nN}-[\mathrm{mM}+\mathrm{nN}-(\mathrm{M} / \mathrm{lnq}) \ln (-\mathrm{L} / \mathrm{mln} \mathrm{l})] \\
& =\mathrm{mM}[\mathrm{Q}-1+\ln (-\mathrm{L} / \mathrm{mln} \mathrm{ln}) / \mathrm{mlnq}] .
\end{aligned}
$$

In this order, the number of survivable weapons, $\mathrm{nN}$, cancels out, as the number of survivable weapons delivered is the same in first and second strikes. Thus, $\mathrm{S}-\mathrm{F}$, and hence the stability index $\mathrm{J}$, depend only on $\mathrm{m}, \mathrm{M}, \mathrm{L}$, and q. They do not depend on the survivable forces, although first and second strikes do. Given the form of S - F in Eq. (12), it is convenient to define the index

$$
\mathrm{j}=\mathrm{J} / \mathrm{kM}=\mathrm{Qm}-(\mathrm{m}-\mathrm{r})=\mathrm{s}-\mathrm{f},
$$

where $s$ and $f$ are the normalized second and first strikes due to vulnerable missiles. This form of the index $j$ shows that stability depends bilinearly on $M$ and $s-f$, in which $s$ depends on $L / n q$ and $f$ depends on $m$ directly and on $L / m$ and $q$ through $r$. In the limit of low forces, neither $s$ or $f$ depends directly on $\mathbf{M}$.

Results. Figure 1 shows $r, Q, f, s$, and $j$ as $m$ varies from 1 to 3 for $p=0.8$. The number of weapons allocated to each vulnerable missile $r$ starts at $\sim 0.73$ and increases as $\ln \mathrm{m}$ in accord with Eq. (8). $Q$ falls as $1 / \mathrm{m}$ in accord with Eq. (9), so $s=m Q=-L / l n q$ is constant. The first strike $\mathrm{f}=\mathrm{m}-\mathrm{r}$ increases almost as rapidly as $\mathrm{m}$. Thus, the index $\mathrm{j}=\mathrm{s}-\mathrm{f} \sim 0.3-\mathrm{m}$ falls to large negative values by $m=3$, denoting instability.

Figure 2 shows $r, Q, f, s$, and $j$ as functions of $m$ for $p=0.6$. Reducing $p$ increases $r$, which decreases $f$, and increases $Q$, which increases $s$. Thus, $j=s$ - $f$ falls, but does so more slowly than in Fig. 1-and from an initial value of about 0.2 - so it does not go negative until $\mathrm{m}$ $\sim 1.75$, which indicates a wider range of parameters before loss of stability. Decreasing the accuracy of vulnerable weapons increases stability for all $\mathrm{m}$. 
Figure 3 shows $r, Q, f, s$, and $j$ as functions of $m$ for $p=0.8$ and $L=1$, which represents a more aggressive attacker than Fig. 1. Increasing $L$ roughly reverses the magnitudes of $r$ and $f$ from Fig. 1. Increased preference for damage to other shifts weapons from counterforce to countervalue attacks. However, $Q$ and $s$ are increased proportionally, so $j=s-f$ experiences offsetting increases in $\mathrm{s}$ and decreases in $\mathrm{f}$ and remains much as in Fig. 1.

Interpretation. The current configuration involves many missiles and many weapons per missile. Such configurations are represented by the far right in Figs. 1-3. To the extent that the low-force results presented above hold at $\sim$ START III levels, they indicate that the most bothersome feature of the current configuration is the deployment of multiple weapons on vulnerable missiles. Survivable missiles cancel out of the analysis.

As missile forces decreased, the stability index $J$ decreases as (s - f)M. Since $s$ and $f$ are independent of $M$, that means for given $m, L$, and $q$, $J$ decreases $\sim M$. For any given $M$, as $m$ decreases, the stability index increases for all parameter variations shown. For nominal parameters the index reaches zero by $\mathrm{m}=1$; for lower $\mathrm{p}$ it reaches slightly above zero. For larger $\mathrm{L}$ it approaches zero while producing more damage. In all cases, the index approaches zero, indicating stability.

There are two ways to achieve stability, which are shown to be independent by the analysis above. The first is to reduce $M$ to zero, which produces stability trivially because there are no missiles. The second is to reduce $\mathrm{s}-\mathrm{f}$ to zero, which can be accomplished by reducing $\mathrm{m}$ to unity at any value of $M$. A variant is suggested by Fig. 2 , which indicates that $s-f \approx 0$ for $m \approx$ 1.75 for $\mathrm{p}=0.6$. For inaccurate vulnerable missiles, multiple weapon vulnerable missiles can be tolerated without reducing stability. However, this result is sensitive to the value of $\mathrm{p}$, which is not known with precision, so this option is not discussed further. The stability properties of the region where $\mathrm{m}<1.75$ and $\mathrm{s}-\mathrm{f}>1$ are discussed elsewhere.

Reconstitution. The above analysis can also be used to study the change of stability indices as $\mathrm{M}$ or $\mathrm{m}$ are increased in the reconstitution of missile forces from low levels. The desired end point of most arms-control discussions is a configuration with a modest number of single weapon vulnerable missiles in a mix with many survivable weapon. Figure 1 shows this configuration would have $\mathrm{j} \approx 0$ and hence be stable. Increasing the number of vulnerable single weapon missiles would not alter the stability index since $\Delta \mathrm{J}=\Delta \mathrm{M}(\mathrm{s}-\mathrm{f})=\Delta \mathrm{M}(0)=0$.

For any $M$, increasing $m$ decreases stability. By $m=2$ the decrease $\Delta j$ is about -0.5 per missile. For 200 vulnerable missiles, that would decrease the bilinear index by $\Delta \mathrm{J} \approx \mathrm{kM} \Delta \mathrm{j} \approx$ $0.001 \times 200 \times(-0.5) \approx 0.1$, which is a significant change. The number of weapons required for that shift is an additional 1 warhead per missile times 200 missiles $=200$ warheads.

Limits on solutions. The analysis and results above are based on the assumption that the number of weapons on missiles is small compared to the number of value targets held at risk, 
which follows from earlier work on the limits of linearization. ${ }^{8}$ As that number is now on the order of 1,000, absent survivable weapons, the analysis above would apply for numbers of vulnerable weapons less than about 1,000. When survivable forces are present, the number of vulnerable weapons must be reduced accordingly for the above results to obtain. Such limits are consistent with negotiating goals beyond START III.

The actual number of weapons allowed depends on the number of value targets on each side, $1 / \mathrm{k}$. The estimates above are based on a nominal value of 1,000 . It is suggested that future policies could greatly reduce the number of targets. For 100 targets, the analysis above would only apply for less than 100 weapons, but the only modification then would be to decrease $\mathrm{M}$ and increase $\mathrm{k}$ by factors of $10 \mathrm{in} \mathrm{Eq.} \mathrm{()} \mathrm{for} \mathrm{J.} \mathrm{As} \mathrm{those} \mathrm{factors} \mathrm{are} \mathrm{multiplicative,} \mathrm{the} \mathrm{changes} \mathrm{are}$ offsetting, and the overall impacts on stability at these reduced force levels would be as discussed above. However, the number of weapons required to degrade stability by a given amount in reconstitution would be reduced accordingly.

Summary and conclusions. This note discusses the variation of strikes and stability indices at force levels below START III, using the strikes, costs, and stability indices produced by an aggregated, probabalistic exchange model to study stability indices at force levels below the number of value targets held at risk, where the costs and optimal allocations are rigorously linear in the forces. In this limit, stability indices depend only on the number of vulnerable missiles and the number of weapons on them. The number of survivable weapons cancels out, because the number delivered is the same in first and second strikes. The stability index reduces to a bilinear product of the number of vulnerable missiles and the difference between the second and first strikes by vulnerable weapons.

As the number of weapons per vulnerable missile decreases, the number of weapons allocated to each vulnerable missile decreases logarithmically, its survival probability falls inversely, and the second strike is constant. Thus, first strikes increases almost as rapidly as the number of weapons, and the index rapidly approaches stability. Decreasing the accuracy of vulnerable weapons increases stability. Increasing the preference for damage to other shifts weapons from counterforce to countervalue attacks but has little overall impact on stability.

The bilinear nature of the stability index at low forces means stability can be gained at any number of missiles by reducing the number of weapons per vulnerable to about unity. Once that is done, further reductions in vulnerable and survivable missiles and weapons do not affect stability, although they do reduce first and second strikes.

The end point of most arms-control discussions is a configuration with a modest number of single weapon vulnerable missiles and many survivable weapons. The analysis above indicates that the latter is irrelevant, but that this configuration would be stable. From it, increasing the number of vulnerable single-weapon missiles would not alter the stability index. 
Increasing the number of weapons per vulnerable missile would decrease stability for any number of vulnerable missiles. Doubling the number of weapons per missile would decrease the stability index by an amount on the order of unity. The number of weapons required for that shift would be an additional warhead per missile times the number of vulnerable missiles, which need not be large. These results are rescaled but not altered for lower numbers of value targets. 


\section{APPENDIX A. EXCHANGE MODEL}

It is possible to model exchanges between equal missile missiles forces in terms of the first, F, and second, S, strikes one side could deliver. That analysis can be extended to unequal forces by treating the strikes F' and S' that the second side forces (denoted by primes for simplicity) could deliver. In it, the symbol convention is that unprime has $M$ vulnerable missiles with $\mathrm{m}$ weapons each and $\mathrm{N}$ survivable missiles with $\mathrm{n}$ weapons each, and prime has $\mathrm{M}^{\prime}$ vulnerable missiles with $m^{\prime}$ ' weapons each and $N$ ' survivable missiles with $n$ ' weapons each. If unprime is the first striker and a fraction $f$ of his weapons is directed at prime's vulnerable missiles, unprime's first strike on value targets is

$$
F=(1-f)(m M+n N) \text {. }
$$

The average number of weapons delivered on each of prime's vulnerable missile is

$$
\mathrm{r}=\mathrm{f}(\mathrm{mM}+\mathrm{nN}) / \mathrm{M}^{\prime} \text {. }
$$

For $r$ large, their average probability of survival is approximately ${ }^{9}$

$$
\mathrm{Q}^{\prime} \approx \mathrm{q}^{\mathrm{r}} \approx \mathrm{e}^{\mathrm{fW}} \mathrm{ln} \mathrm{q} / \mathrm{M}^{\prime},
$$

where $q=1-p$, and $p$ is the attacking missile's single shot probability of kill, which is taken to be $\mathrm{p}=0.6$ for all missiles. Prime's second strike is

$$
S^{\prime}=m^{\prime} M^{\prime} Q+n^{\prime} N^{\prime} \approx m^{\prime} M^{\prime} q^{r}+n^{\prime} N^{\prime},
$$

which is delivered on value, as missiles remaining at the end of the exchange are taken to have no value in this two strike engagement. The corresponding equations for prime's strike can be derived either by repeating the logic from his perspective or simply by conjugating the equations above, i.e., interchanging primed and unprime symbols in Eqs. (A1) - (A4).

\section{APPENDIX B. STRIKE COSTS AND STABILITY INDICES.}

These first and second strike magnitudes can be converted into the costs of striking first and second through exponential approximations to the fractions of value targets destroyed. The cost of damage to unprime when he strikes first is approximated by

$$
\mathrm{C}_{1 \mathrm{~s}}=\left(1-\mathrm{e}^{-\mathrm{kS}}\right) /(1+\mathrm{L}),
$$

where the constant $k \approx 1 / 1000$ is roughly equal to the inverse of the size of unprime military value target set that prime wishes to hold at risk, ${ }^{10}$ and $\mathrm{L}$ is a parameter. For a small prime second strike, $C_{1} \sim \mathrm{kS}^{\prime} /(1+\mathrm{L})$, which is small; for a large prime second strike, $\mathrm{C}_{1} \sim 1 /(1+\mathrm{L})$. The cost to unprime of incomplete damage to prime is approximated as

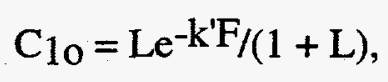


where $k^{\prime} \approx 1 / 1000$ is roughly the inverse of unprime value that unprime wishes to hold at risk. $\mathrm{C}_{10}$ is small for $\mathrm{F}$ large and large for $\mathrm{F}$ small. $\mathrm{C}_{1 \mathrm{~s}}$ and $\mathrm{C}_{10}$ are formally incommensurate, as they represent damage to different parties, but a conventional approximation to a total cost for striking first is their weighted sum ${ }^{11}$

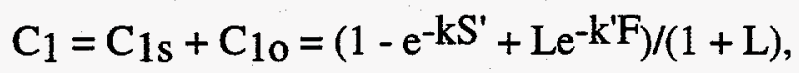

where $L$ is a constant that represents the attacker's relative preference for inflicting damage on the other and preventing damage to self. $L$ small means that as a first striker, unprime is primarily concerned about denying damage; $L$ large means he is more concerned about inflicting damage on the other. The conventional assumption that $\mathrm{L} \leq 1$ and construction of $\mathrm{C}_{1}$ as a weighted average is plausible but not unique. ${ }^{12}$ Second strike costs are also composed of damage to self and other. The former is approximated for unprime by

$$
\mathrm{C}_{2 \mathrm{~s}}=\left(1-\mathrm{e}^{-\mathrm{kF}}\right) /(1+\mathrm{L})
$$

the latter by

$$
\mathrm{C}_{20}=\mathrm{Le}^{-\mathrm{k}} \mathrm{S} /(1+\mathrm{L})
$$

and the total cost for unprime striking second by

$$
\mathrm{C}_{2}=\mathrm{C}_{2 \mathrm{~s}}+\mathrm{C}_{2 \mathrm{o}}=\left(1-\mathrm{e}^{-\mathrm{kF}}+\mathrm{Le}-\mathrm{k}^{\prime} \mathrm{S}\right) /(1+\mathrm{L}),
$$

The first and second strike costs for prime can be obtained either by re-deriving these results from prime's viewpoint or by conjugating Eqs. (B3) and (B6), which introduces a second constant L', which reflects prime's attack preference ${ }^{13}$

There is some arbitrariness in converting $\mathrm{C}_{1}$ and $\mathrm{C}_{2}$ into stability indices. ${ }^{14}$ It is conventional to use the ratio of first and second strike costs, $I=C_{1} / C_{2}$, as a stability index for unprime, and $\mathrm{I}^{\prime}=\mathrm{C}_{1} / \mathrm{C}_{2}{ }^{\prime}$, as a stability index for prime. When this index is large, there is no advantage to striking first, and when it is small, there is an advantage, which may be perceived as an incentive to first attack in a crisis. For unequal forces, the product of the stability indices of the two sides is used as a compound index

$$
\text { Index }=\mathrm{I} \times \mathrm{I}^{\prime}=\left(\mathrm{C}_{1} / \mathrm{C}_{2}\right)\left(\mathrm{C}_{1}^{\prime} / \mathrm{C}_{2}{ }^{\circ}\right) \text {. }
$$

\section{APPENDIX C. OPTIMAL ATTACK ALLOCATION.}

For unprime, optimal attack allocation amounts to choosing $f$ that minimizes his first strike cost $C_{1}$, which is accomplished by differentiating Eq. (B3) with respect to $f$, setting the result to zero, and solving for $f$. For large forces the resulting equation is transcendental, but the 
optimal $\mathrm{f}$ for small forces $(\mathrm{F}, \mathrm{S} \ll 1 / \mathrm{k}$ ) holds sufficiently accurately for moderate forces (F, $\mathrm{S}<$ $1 / \mathrm{k}$ ), for which Eq. (B3) reduces to

$$
(1+L) C_{1} \approx k\left(m^{\prime} M^{\prime} e^{f W l n q} / M^{\prime}+n^{\prime} N^{\prime}\right)+L\left[1-k^{\prime}(1-f) W\right],
$$

whose derivative with respect to $f$ has a minimum at

$$
f_{0}=\left(M^{\prime} / W \ln q\right) \ln \left(-L^{\prime} / k^{\prime} / \ln q\right) \text {. }
$$

The equation for prime's first strike allocation is the conjugate of Eq. (C2). $f_{o}$ scales directly on the opponent's vulnerable missiles $M$ ' and inversely on one's own total weapons $\mathrm{W}=\mathrm{mM}+\mathrm{nN}$. In a first strike, the distinction between vulnerable and survivable missiles is not significant, so the degree of fractionation of each is unimportant, only $\mathrm{W}$ matters. It is plausible that the number of weapons allocated to missiles should be proportional to the number of missiles, i.e., $\mathrm{Wf}_{\mathrm{opt}}$ M', so that the vulnerable missiles are roughly covered. If in addition, the number of vulnerable weapons $\mathrm{mM}$ is proportional to the number of survivable weapons, $\mathrm{mM} \sim \mathrm{nN}$, then $\mathrm{f}_{\mathrm{o}} \alpha$ $\mathrm{M}^{\prime} / \mathrm{mM}$., i.e., $\mathrm{f}_{\mathrm{O}}$ scales in proportion to the relative number of the opponent's vulnerable missiles and inversely with one's own weapon inventory.

If the number of vulnerable missiles on each sides change proportionally, $M \sim \mathbf{M}^{\prime}$, then $f_{o} \sim 1 / m$. If the number of weapons per missile does not change, $f_{o}$ is constant. For $m=n$, i.e., equal fractionation of vulnerable and survivable weapons, $W=m(M+N)$, so that the allocation only depends on the total number of missiles, not on whether they are vulnerable or survivable. To first order it is unprime's weapons per missile that determines his allocation; prime's weapons per missile $\mathrm{m}^{\prime}$ enters only logarithmically, as do $\mathrm{L}, \mathrm{k}$, and $\mathrm{k}^{\prime}$. The allocation decreases with $L$; it is insensitive to prime's attack parameter $L$ ', which does not enter $C_{1}$. 


\section{References}

1. G. Canavan, "Stability of Unsymmetric Forces," Los Alamos report LA-UR-97-1133, March 1977.

${ }^{2}$. G. Kent and R. DeValk, "Strategic Defenses and the Transition to Assured Survival," RAND Report R-3369-AF, October, 1986.

3. G. Canavan, "Stability Issues in Reconstitution by Weapon Addition," LA-UR-97-3149, August 1997, Eqns. (23)-(24).

4. G. Canavan, "Stability Issues in Reconstitution by Weapon Addition," op. cit., Eqns. (25)-(27).

5. A. Piontkovsky, "New Paradigm of Strategic Stability," A. Zichichi ed, International Seminar on Nuclear War and Planetary Emergencies (London, World Scientific, 1993)

6. G. Canavan, "Attack Optimization for Unequal Moderate forces," Los Alamos report LA-UR97-2195, June 1997.

7. G. Canavan, "Linearity of Missile Allocation Optimization," Los Alamos report LA-UR-973569, August 1997.

${ }^{8}$. G. Canavan, "Linearity of Missile Allocation Optimization Optimization," op. cit.

9. G. Canavan, "Probability of Survival from Multiple Weapon Attacks," Los Alamos report LAUR-97-664, February 1997.

10. G. Canavan, "Costs of Strikes Between Vulnerable Missile Forces," Los Alamos report LAUR-97-, February 1997.

${ }^{11}$. G. Kent and R. DeValk, "Strategic Defenses and the Transition to Assured Survival," op. cit.

12. G. Canavan, "Stability at Symmetric Low Force Levels," Los Alamos report LA-UR-961631, May 1996.

13. G. Canavan, "Destabilizing Effects of Perceptions," Los Alamos LA-UR-96-1742, May 1996

14. G. Canavan, "Impact of Differing Metrics on Crisis Stability Analyses," A. Zichichi ed., International Seminar on Nuclear War and Planetary Emergencies, 18th Session: Global Stability Through Disarmament (London, World Scientific, 1993). 

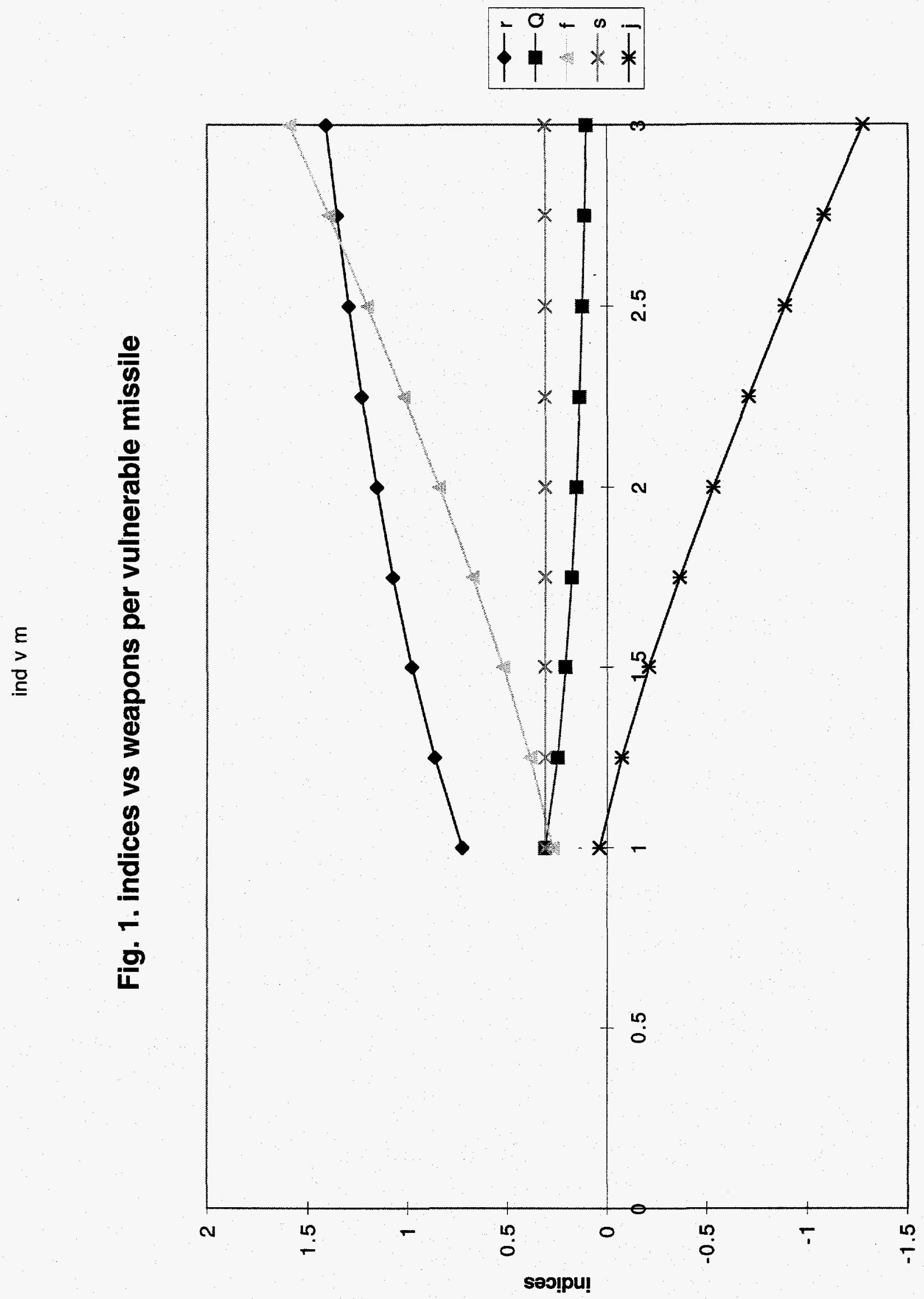

E $\stackrel{\bar{g}}{\mathbb{8}}$ 


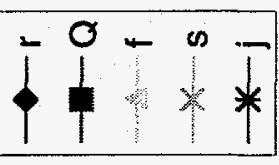

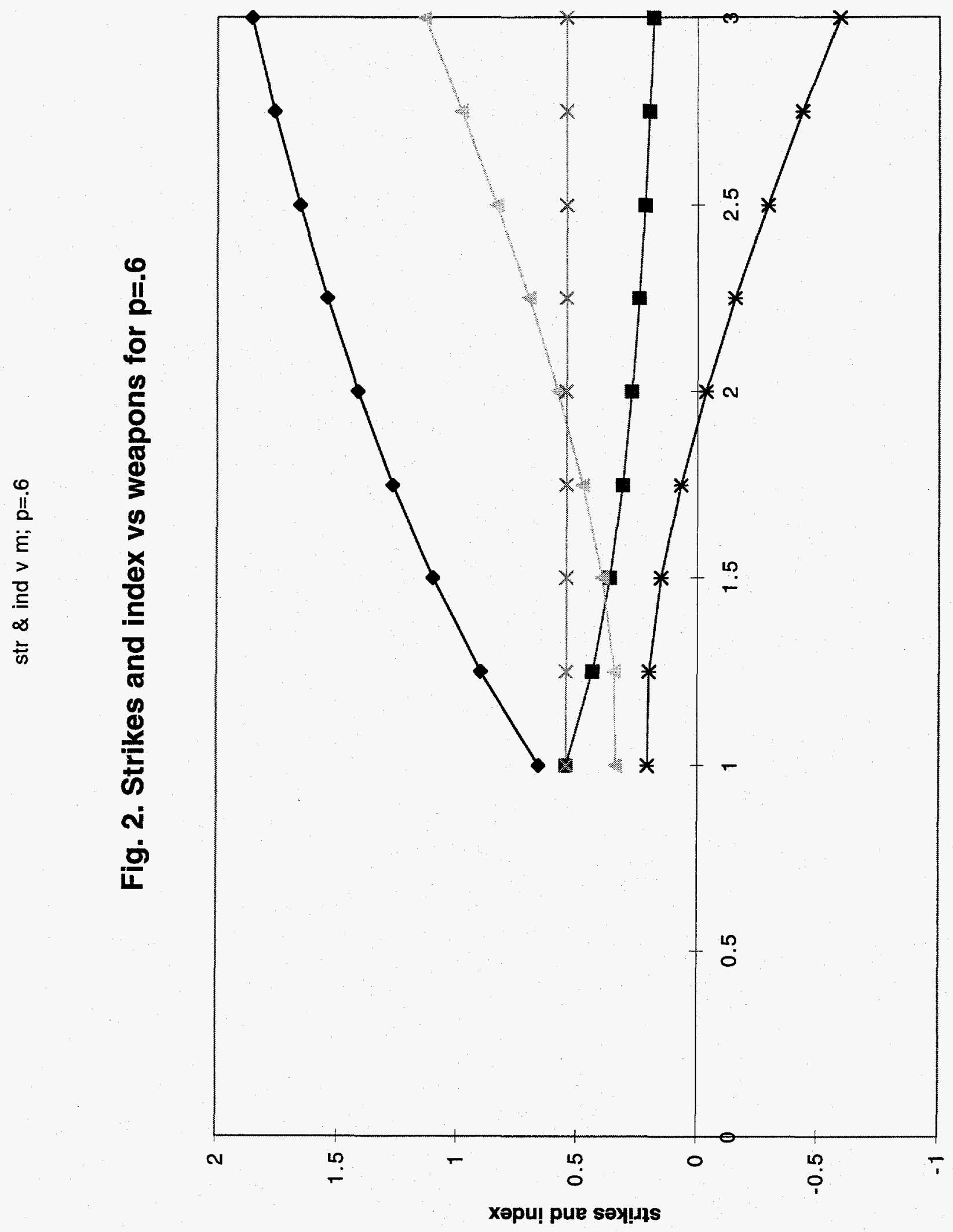

E $\frac{-}{8}$ 


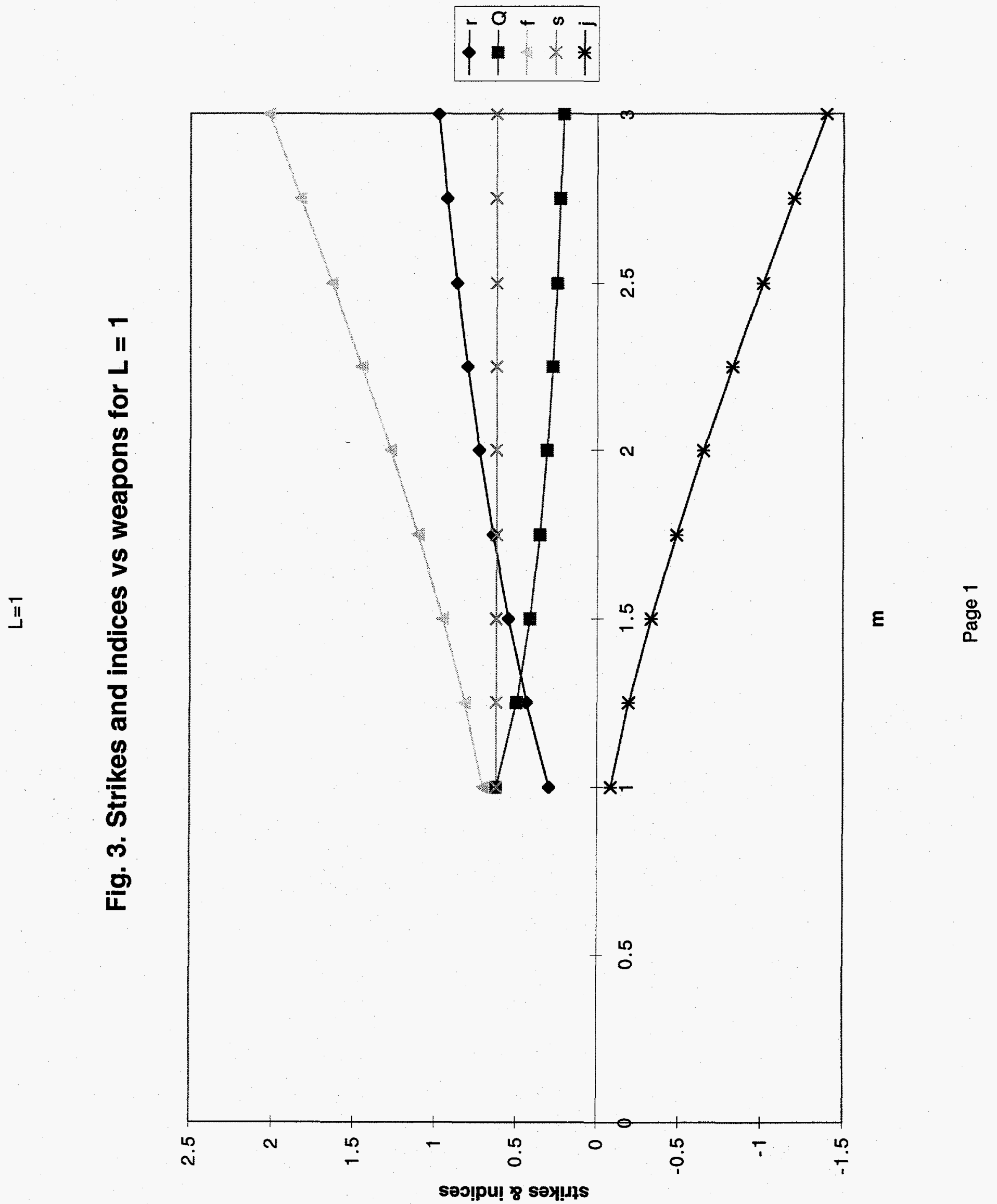

